\title{
User Loyalty and Online Communities: Why Members of Online Communities are not Faithful
}

\author{
Petter Bae Brandtzæg \\ SINTEF \\ Forskningsvn. 1 \\ 0314 Oslo, Norway \\ $+4792806546$ \\ pbb@sintef.no
}

\author{
Jan Heim \\ SINTEF \\ Forskningsvn. 1 \\ 0314 Oslo, Norway \\ $+4722067569$ \\ jheim@sintef.no
}

\begin{abstract}
Online communities are getting increasingly important for several different user groups; at the same time, community members seem to lack loyalty, as they often change from one community to another or use their community less over time. To survive and thrive, online communities must meet members' needs. By using qualitative data are from an extensive online survey of online community users and a representative sample of Internet users, 200 responses to an open question regarding community-loyalty was analyzed. Results show that there are 9 main reasons why community-users decrease in their participation over time or, in simple terms, stop using their online community: 1) Lack of interesting people/friends attending, 2) Low quality content, 3) Low usability, 4) Harassment and bullying 5) Timeconsuming/isolating, 6) Low trust, 7) Over-commercialized, 8) Dissatisfaction with moderators and 9) Unspecified boring. The results, design implications and future research are discussed.
\end{abstract}

\section{Categories and Subject Descriptors}

C.2 [Computer-Communication Networks]: C.2.1 Network Architecture and Design K.2.0 - Network communications [Computers and society]: General and H5.2 [User Interfaces]: User centered design.

\section{General Terms}

Design, Human Factors

\section{Keywords}

Online communities, User loyalty, Participation, Design, Trust, Usability, Social interaction.

\section{INTRODUCTION}

Online communities have changed the way people use new media. They create personal profiles, share photos, videos, and blogs, and produce more user-generated content in general [3, 2]. Several new reports show an exponential increase in online communities and user-generated content. Communities such as MySpace have generated more than 130 million registered users and are still growing. An OECD report [23] states that there is a growing interest in user-generated content. A survey of academic

Permission to make digital or hard copies of all or part of this work for personal or classroom use is granted without fee provided that copies are not made or distributed for profit or commercial advantage and that copies bear this notice and the full citation on the first page. To copy otherwise, or republish, to post on servers or to redistribute to lists, requires prior specific permission and/or a fee. The Second International Conference on Intelligent Technologies for Interactive Entertainment (ICST INTETAIN '08). January 8-10, 2008, Cancun, Mexico. Copyright 2008 ICST. ISBN 978-963-9799-13-4. community members in a study conducted in 2005 in the USA found that $90 \%$ of undergraduates participated in a social network community, primarily Facebook, MySpace, and Friendster [20]. Similarly, in the UK more than 70\% of 16- to 24-year-old Internet users use social networking websites [15].

These rapid changes in usage patterns and technological advances are reshaping the new media landscape and pose several research challenges [7]. Users are not only drawn to online communities for the content and services the communities provide, ease of use might also be an important issue. The key challenges facing online communities are therefore not simply technological but also psychological, such as: usage behavior, social interaction, social organization, motivations, attitudes and loyalty $[17,1,12]$.

An online community will not survive without lasting user motivation and user participation in terms of social interaction and the production of user-generated content. In simple terms, if users do not like the service, which could be due several factors, they will not keep using it or will use it less than before. Online communities must provide the benefits and experiences that members seek, in order to gain end-user loyalty [1, 2, 11].

However, what makes successful online communities in terms of end-user loyalty is often poorly understood; yet, this is critical knowledge for designers and human factor engineers building online communities. Therefore, on a general level, it is necessary to understand the people who will use the service, the goals or tasks they have, and their context of use [8]. The goals or tasks people have in online communities are often seen in relation to motivational issues. According to Watersone [21], motivation theories have led researchers to focus on factors that inspire people to take part in an online community and make the community successful over a longer time period.

Powerful indicators of an online community include the following: 1) people with shared interests, 2) experiences and needs, 3) supportive and sociable relationships, 4) strong social feelings of belonging, and 5) a sense of shared identity [6, 18, 21]. In addition, there has been a specific research focus on how motivation can encourage community members to participate in terms of contributing and sharing information or media content [6].

Kollock [12] has suggested motivational factors such as the expectation of generalized reciprocation, building a reputation, gaining a feeling of self-efficacy, and altruism. Others have suggested some additional possible motivational factors, such as the following: 1) user visibility, 2) feedback channels, 3) a large user population, 4) low barriers for entering the community, and 5) accessibility and usability for end-products $[11,6]$. 
However, dynamic interactions between the determinants of success in online communities, such as barriers to entry, loss of motivation, and declines in participation, have not been fully investigated. To address the limitations of research in this area, this paper approaches online communities from the perspective of end-user loyalty, by asking individuals why they choose to drop out of communities or use them less.

The study presents empirical data gathered from four Norwegian online communities, combined with data from a representative sample of Internet users. 200 users are analyzed regarding their answer to an open question about why they decided to leave, or to use an online community less than before. This study aims to conduct an in-depth analysis of 200 of the free text answers most elaborated upon.

The data investigated are up-to-date, and were collected in March 2007. They should be representative of a period when the usage of online communities had increased strongly, not just among expert users, but also among non-professional users. Further, as Norway has a high coefficient of diffusion of new media technologies in comparison to many other Western countries [9], it is a particularly interesting location for research on this topic.

\subsection{Online community and emergent trends}

This section describes emergent trends of online communities, based on a review of recent reports and research. This will serve as a basis not just to explain the specific characteristics of current online communities, but also how and why online communities are gaining a broader popularity among several different user groups. Further, this section can help readers to understand the increasing complexity that users of online communities are confronted with, and how online communities more or less represent a paradigm shift on the web.

First, there is said to be no accepted or universal definition of online community. However, on a general level, online communities can be divided into different categories [16]:

- Person-oriented communities: Communities where the person and social interaction are in focus. Examples are MySpace, Facebook, Friendster, Bebo, Orkut, Windows Live Space, and Hi5.

- Professional communities: Communities that focus on business networking. Examples are LinkedIn and itLinkz.

- Media-oriented communities: Communities that focus on the distribution and consumption of user-generated multimedia content, such as video, music or photos. Examples are YouTube and Flickr.

- Virtual-world communities: Communities that are essentially a 3-D virtual world, built and owned by their residents (the users). A typical example is SecondLife.

- Mobile communities: Communities that make it possible to have direct and indirect contact with community friends and makes updates on the move. Typical examples are Twitter and MyPlace.

Despite this superior categorization of "online communities", the term has different meanings for different people as well as in diverse disciplines. This study will approach online communities using the definition suggested by Jenny Preece [17]. She defines an online community as a group of people who interact in a virtual environment. These communities have a purpose, are supported by technology, and are guided by norms and policies.

The following description of trends (see Figure 1.) in online communities is categorized into the four parts that constitute an online community according to the definition by Preece [17]:

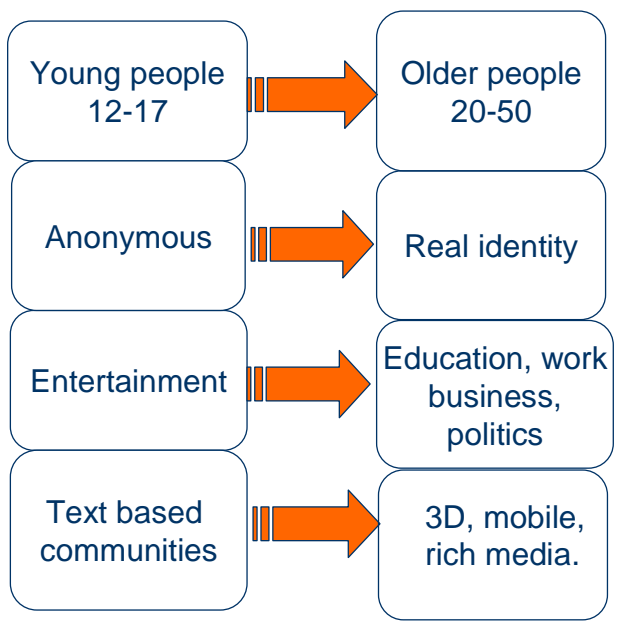

Figure 1. Trends in online communities

1. People: User groups inside online communities have for some years been populated mainly by the younger users aged 12-17. This is now changing; the largest growing user group in online communities is said to be people older than 35 years [16]. Several communities also make it possible to mix professional tasks with leisure and entertainment activities, blurring the border between work and private life (e.g., Facebook). Further, people are dissolving the traditional barriers between mainstream and homemade media [3]. Broadband distribution and multimedia content devices are gradually transforming users from being content consumers into content creators and content traders, blurring the distinction between audiences and actors.

2. Policies/norms: Users were initially anonymous, using nicknames when using online communities, but people are increasingly using their real identities on the Internet (e.g., Facebook).

3. Purpose: People mainly use online communities for entertainment [2], but are increasingly using online communities for working and professional networking purposes (e.g., LinkedIn and Facebook). Further, community members are dedicated to "online communities" as such, but not to one single community. They may attend different communities to fulfill different purposes. A new Norwegian study shows that community members are not loyal to any particular community, and the majority of members visit two or more communities each day; within a month, the majority has visited four or more. Users also seem to switch frequently from one community to another [2].

4. Technology: Online communities have changed from using simple text-based environments to integrating more multimedia tools and applications to enhance user generated audio-visual content and 3D. Several 
communities are also getting mobile (e.g. Facebook and Twitter). Finally, online communities play an important role in the media convergence (e.g., YouTube, SecondLife and Facebook) [2].

Further, online communities in terms of web 2.0 technologies and social networking applications are being referred to as "Community 2.0," a term that refers to online communities characterized by rich user-generated content (video, audio, pictures) and dynamic interaction among multiple users in a virtual environment [22].

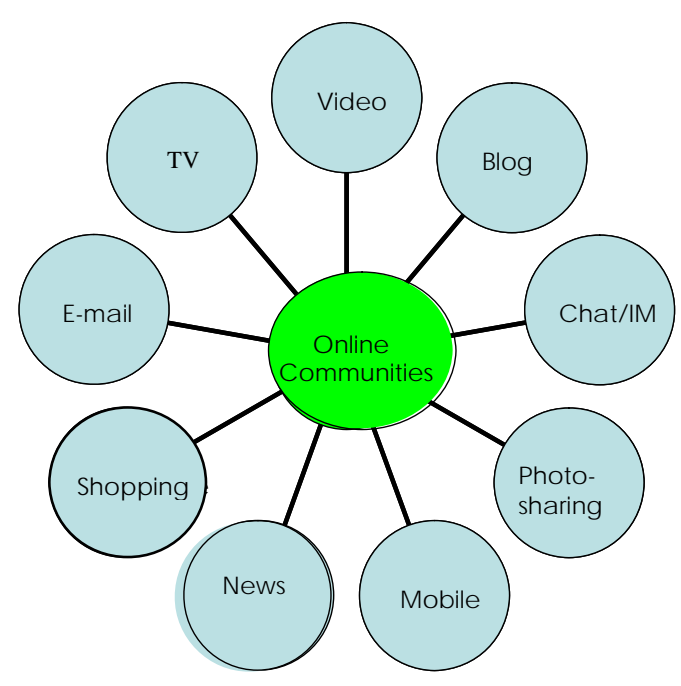

Figure 2. Community 2.0 solution or the "all-in-one-placesolution": Increasing opportunities and complexity

Examples of Community 2.0 applications are social networking services, such as MySpace and Facebook, which allow users to easily create their own profiles and user generated content. Further, Community 2.0 solutions indicate a shift toward a convergence of different media, functions and services such as blog, mobile, IM, wiki, e-mail, video, news, shopping, etc.: an ”all-in-one-place-solution” (see Figure 2).

This new way of using the Internet demonstrates increasing user opportunities for content creation and sharing in one single solution on the web. In addition, this solution is part of a social context, the user network. Users may therefore simplify much of their web life onto a single home page, and can put together their own universe. Such communities may help the user to cope in an increasingly fragmented media landscape; on the other hand, this is increasing complexity of the community interface in terms of its low level of simplicity or usability.

According to Jacob Nielsen , in most online communities there exists a "90-9-1 rule":

- $\quad 90 \%$ of users are "lurkers" who never contribute

- $\quad 9 \%$ of users contribute a little, and ...

- $1 \%$ of users account for almost all the action.
This rule points out how low or infrequent participation among most community members is - there is a participation inequality. This indication is, however, supported by the view of the lack of end-user loyalty among online community users, users switching from one community to another: Users that not really engage towards a community by contributions and participation in general. As pointed out by Watersone [23], we still need more knowledge about motivations or de-motivations among the members of online communities. This will help us to understand how non-professional users can be supported in creating and sharing media content in new online communities, and how we can ensure end-user loyalty.

\subsection{Research questions}

This study will investigate end-user loyalty to online communities, in regards to why people stop using online communities or use them less over time. As mentioned in the introduction, the issue of user loyalty and online communities has been largely ignored in previous research.

RQ: Why do online community users stop using or use online communities less over time?

The next section present the methods and the sample investigated in this study.

\section{RESEARCH METHOD}

The study took place in March 2007, over a four-week period. We investigated a total of five samples in two stages: 1) four wellknown online communities in Norway and 2) one representative sample of Internet users in Norway.

\subsection{Four online communities}

The four online communities were chosen because they were among the most popular and well-known in Norway at the time of our study. They also have features that enable users to contribute various types of content. All the communities we investigated can be regarded as person-oriented communities: communities where the person and social interaction are in focus. The communities were the following: 1) Biip.no, 2) HamarUngdom.no, 3) Nettby.no, and 4) Underskog.no (See Table 1. below.)

As shown in Table 1, there are some differences between the communities in terms of the age of the communities and the number of members. HamarUngdom is particularly old (founded in 2002). One community (Underskog) requires an invitation to join, while the others are open to all. The Underskog-community is also the smallest (10 000 members) and the most focused community, since the goal is to develop a user-generated cultural calendar.

Table 1. The four communities in this study

\begin{tabular}{|l|l|l|}
\hline Communities & Origin & $\begin{array}{l}\text { Number of } \\
\text { Members }\end{array}$ \\
\hline Biip & 2005 June & 280000 \\
\hline Hamar-Ungdom & 2002 August & 190000 \\
\hline Nettby & 2006 September & 320000 \\
\hline Underskog & 2005 November & 10000 \\
\hline
\end{tabular}


The users of Underskog and Nettby are slightly older than for the other communities. These communities are not just targeting teenagers. Underskog targets an older (approximately 25-40 years) and better-educated part of the population, with cultural interests, and particularly in the Oslo area. Nettby approaches a broader segment of the population, and recruits its users from the largest online newspaper in Norway, VG Nett (www.vg.no). VG Nett is accessed by more than one quarter of the population of Norway.

To collect data, we used online user surveys, which gave us the opportunity to access a very large number of users within these communities. We used SurveyMonkey as a survey tool. We urged the community owners to distribute the survey to all their members inside the community, either by a tag on the members' user profiles or with a message. This was the case with Biip and HamarUngdom, while with Nettby the survey was merely introduced by a banner urging users to participate: "Please tell us your opinion about Nettby.no.” The Underskog community owners preferred to have us, the researchers, inform their members about the survey. We did so by posting information on blogs inside the Underskog community.

To motivate users to participate in the survey and complete the questionnaire, all the users in the four communities could participate in a raffle and win a travel gift coupon worth 10000 Norwegian Kroner if they were willing to leave their email address at the end of the survey. Users younger than 15 years were urged to inform their parents about their participation.

A total of 5223 people from the four online communities responded to the survey. The response rate to the surveys in the communities was as follows:

- $\quad$ Biip.no (N 2778)

- $\quad$ Nettby.no (N 512)

- Underskog.no (N 335)

- Hamarungdom.no (N 1598)

\subsection{Representative sample of Internet users}

The second data collection was conducted in order to achieve a representative picture for our research questions. This was done by collecting data from a panel of users that was nationally representative of Norwegian Internet users. The data collection was performed by Norstat at the same time as the community surveys in March 2007, using an online survey tool that they host. Norstat is a Nordic market research company, best known for its specialization in the field of information and data gathering. WebSurvey $^{\mathrm{TM}}$ is Norstat's solution for web surveys. WebSurvey ${ }^{\mathrm{TM}}$ is easy to use and makes low demands on the client computer.

Five hundred people participated in the survey. Participants were representative of the Norwegian Internet population in terms of geographical location, gender, and age (15-74 years); this group is called "Rep. Sample” in Figure 3.

There were 5733 respondents in total in the five samples. Figures 3 and 4 show the sample size and gender distribution of the five samples in this study.

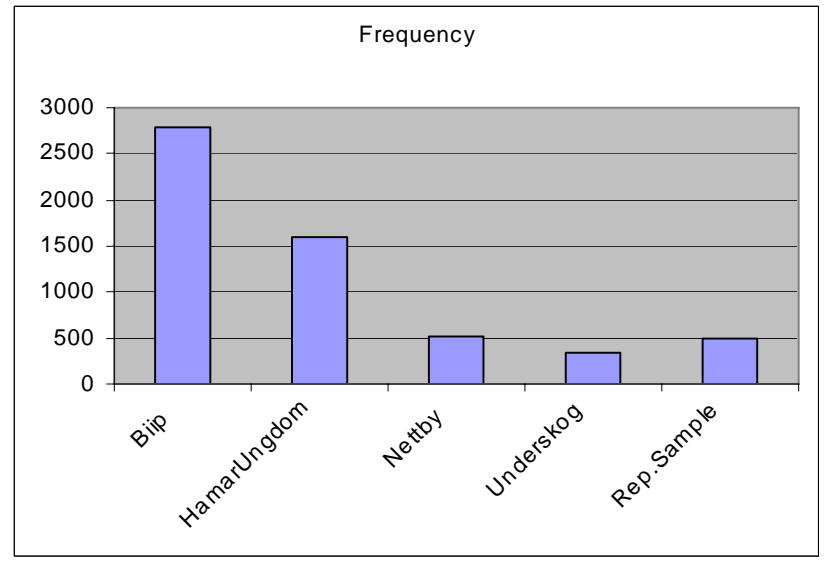

Figure 3 Sample size frequencies inside each community and the representative sample

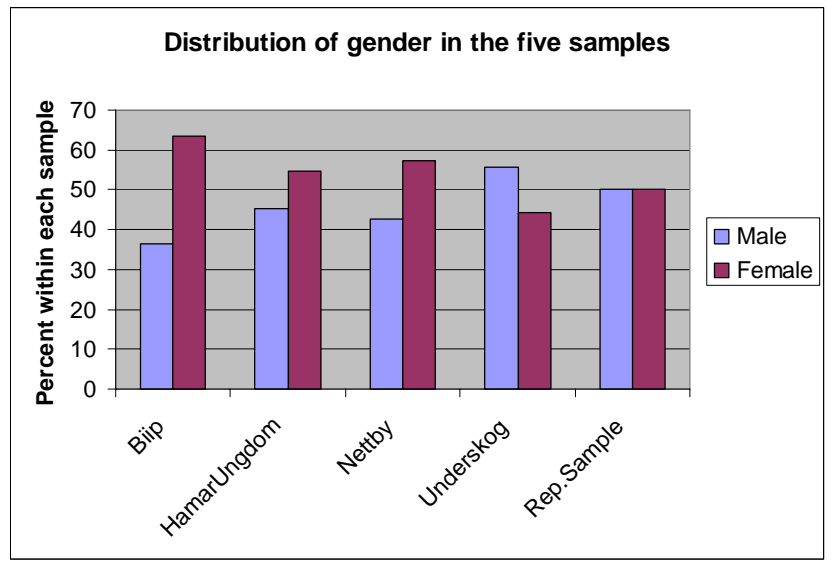

Figure 4 Distribution of gender inside each community and the representative sample

We used both open-ended and fixed-choice responses, but will only focus on one open-ended question in this study. This is also the only part of the study that explicitly covers the research question regarding end-user loyalty to communities. The openended question given to all respondents inside the five samples was as follows:

Have you stopped using some online communities or are you using them less than before?

\subsection{Content analysis}

With more than 5000 respondents, we needed to reduce the comprehensive content of qualitative information into a manageable portion of user statements. To avoid user statements lacking meaning or with low information value, we decided to select the 200 user statements with the highest number of words. These user statements were obviously given by users who had had time to reflect on the questions and replied in a way that made it significant for us to interpret. 
We decided to approach the data using content analysis to be able to reduce it to a manageable scale. Our content analysis was combined with frequency counts using Excel worksheet. Like any other form of content analysis, we defined some categories that were reflected in the data and sorted those into themes. Content analysis is supposed to be useful to describe and make inferences about the characteristics of communications, and patterns of usage, as well as making inferences about the consequences of communications [10]. Using content analysis to approach user statements related to end-user loyalty in online communities could therefore be useful.

In the next section, we supplement the analyses with systematic quotations from the interviews to illustrate the results. Below are the extracted results.

\section{RESULTS}

To discover the most frequent reason for being less active or terminating use of online communities we combined the content analysis with counting number of reported reasons that belong to different categories. A total of ten categories were identified. The most frequent reasons are seen in ranked order, with the most frequent reasons first (see also Table 2).

1. Lack of interesting people/friends attending: This was associated with lack of interesting people and friends inside the community.

2. Low quality content: This was related to low content quality, in terms of too many recurrences, little content variation (nothing new is happening), and in general uninteresting content.

3. Low usability: This was related to usability issues in terms of complex user interfaces.

4. Harassment/bullying: This was related to users reporting harassment or bullying inside communities.

5. Time consuming/isolating: This was related to users claiming too much time to follow up on the interaction inside the communities,

6. Low trust: This was related to users reporting less trust related to the community because many of the other users had fake IDs. Another reason to lower trust was too much bad comments and dirty talk among users.

7. Over-commercialized: This was related to users reporting de-motivation because of too many advertisements inside the community, or that it was too expensive to buy extra user services inside the community.

8. Dissatisfaction with moderators: This was related to users reporting dissatisfaction with moderators, because they were too eager to report others or just did a bad job.

9. Unspecified boring. This was related to users that complained about the community getting boring without reporting any specific reason.

10. Other: This was related to other diverse complaints or users just reporting the fact that they had stopped using a community or were using it less.
Table 2. Reasons to stop using a online community or using it less over time

\begin{tabular}{|l|c|}
\hline \multicolumn{1}{|c|}{ Reasons } & \multicolumn{1}{|c|}{$\begin{array}{c}\text { Number of reported } \\
\text { reasons and in \% }\end{array}$} \\
\hline $\begin{array}{l}\text { 1. Lack of interesting } \\
\text { people/friends attending }\end{array}$ & $62(24 \%)$ \\
\hline 2. Low quality content & $59(23 \%)$ \\
\hline 3. Low usability & $45(18 \%)$ \\
\hline 4. Harassment/bullying & $24(9 \%)$ \\
\hline 5. Time-consuming/isolating & $16(6 \%)$ \\
\hline 6. Low trust & $15(6 \%)$ \\
\hline 7. Over-commercialized & $15(6 \%)$ \\
\hline 8. Dissatisfaction with moderators & $3(1 \%)$ \\
\hline 9. Unspecified boring & $3(1 \%)$ \\
\hline 10. Other & $15(6 \%)$ \\
\hline & $257(100 \%)$ \\
\hline
\end{tabular}

*There was in total 200 participants, but 57 participants reported two reasons.

Dissatisfaction with the social interaction being experienced is viewed as the most frequent reason for leaving a community or using it less. Moderators, harassment, and trust may also be regarded as social issues that influence people's perception of the online community. Further, usability issues and content quality seem to be highly significant reasons to stop using or use a community less.

The following section gives some examples and quotations from the survey participants related to the five most frequent categories identified.

(1) Lack of interesting people/friends: Users, reported too few interesting people inside the community as a prime reason to terminate their community membership. This could be due to several factors. One was that there were too few or no online community members that they knew or who lived nearby. For example, MySpace can often produce a lot of friends that you do not really know and rarely, if ever, will meet in real life. Another reason was that "all my friends had stopped using the community" or that other types of people suddenly joined the community and it got less interesting there.

Further, dissimilar age groups and people with interests different from the users were said to be an important determinant in not using the community or using the community less. Many communities are targeting younger age groups, so several users complained about too many youngsters inside the community. Others claimed that they had grown too old for their community, while others and in particular younger girls reported that there were too many older men in the community. This fact was viewed as problematic; because it was experienced as threatening in terms of sexual harassment (see point 4.).

I have stopped using a music community since other types of people suddenly joined the community and 
made the community less interesting to participate in...(25 year's old, male).

I use Twitter less since some of my nearest friends stopped using it...(24 year's old, female).

(2) Low quality content: 23 percent of the users reported that they had stopped using a community or used a community less because it has too few content updates and little variation. Other reasons were related to the following:

- Too few content updates and little content variation or variation related to creation and sharing opportunities.

- Too much focus on things/content that the user is not interested in.

- Too few things to do inside the community in terms of different types of add-on services, applications (e.g. music, video, blog, news etc.) and too few tools for making the user profile look good

- Too many recurrences, and little or nothing new happening inside the community.

Just communication or social interaction among users is not enough: there should be something to do, a common goal, and some common activities. In addition, people report losing interest after a time (e.g., YouTube was interesting for the first few months, but after a while you get bored).

Online communities have a tendency to be interesting in the first phase, but after a while the discussions and content often repeat (...) (28 year's old, male)

It is fun to be on Nettby Max. You can fix and do tricks on your profile, make it nice to look at, and that is fun...There is more to do there than on other sites I have been to. (18 year's old, female)

I have stopped using Blink, since it is an online community for people who are looking for dating and sex (...) You can't either not use this forum to discuss serious things (17 year's old, female).

(3) Low usability: Among the comments from the 18 percent of the users who reported communities to be difficult to use, were the following descriptions: it was too much hassle to change profiles; the service was too slow; the user interface was messy; users did not understand how to use different services; and several general user problems. Users also reported that some online communities had too many updates, adding new services or functions. These updates caused a lot of frustration and usability problems for the users later on.

I have nearly stopped using Biip.no, because it is frequently updated. Several times the visitor book didn't show up, and other times it has not been possible to comment on pictures (...) (16 year's old, female).

MySpace, I have nearly stopped using (...) you need a lot of codes etcetera on the profile. Too advanced for me (16 year's old, female).
(4) Bullying/harassment: Bullying and harassment was reported to be a reason to stop using a community among 9 percent of the users. Several reported that they had experienced sexual harassment from older boys or men; they asked these community girls for "cam" (web-cam sessions) and sex, or made bad comments in a sexual form.

There are large gender differences when it comes to harassment; more girls than boys experience this. 14 girls claimed to have dropped out or used the communities less because of sexual harassment, but no boys made the same claim. Nearly all of these girls were teenagers.

However, a lot of the communities where they report experiencing sexual harassment are quite obscure and have names such as deiligst.no and penest.no. These are typical 'hot or not' communities, where people upload quite revealing pictures of themselves.

I used to play Habbo before (...) I did not find out if the people I talked to were old or young. I therefore thought it was a huge risk that I may have talked to pedophiles (15 year's old, female).

I have stopped using Blink, It is nasty when very old men start writing to or chatting with younger girls (17 year's old, female).

(5) Time consuming/isolating: In total, 6 percent of the users claimed that the most important reason to stop using or use an online community less was that it took too much time. Some reported that they were not students anymore, and a new life with regular working hours made it impossible to follow up the online community life. Others thought community-usage in general was too time-consuming, and that it was stressful to follow up on interaction inside the communities. Some also reported that this online interaction took time from real-life connections. Another less frequent reason was that it took too long to get to know others in social interactions inside online communities; therefore, contacts also became superficial. In the end, users felt that they did not really get to know other people.

Yes, I am less active in some online communities, because I have a job, other leisure occupations that take up my time. (17 year's old, female).

(6) Low trust: 6 percent of the users reported their loyalty to the community to be a problem, since other members of the community misused the service by faking identities or using bad language.

I have stopped used Blink (....) It is not personal anymore, and are lot of fake people that not use it serious (17 year's old, female).

\section{DISCUSSION}

The in-depth analyses performed in this study shed light on many of the unique properties of online communities, and the results contribute to the body of knowledge by providing new knowledge on end-user loyalty in online communities. One of the main challenges for user research in this domain is the rapid change that is taking place in both technological development and user 
preferences. Therefore, this section will, besides discussing the results of the study, look into possible user requirements or design implications based on the empirical results, which should be taken into account in the development of future online communities to ensure end-user loyalty.

Low satisfaction with the people or the social interaction inside the community is the most important factor resulting in disinterest in the use of online communities. Although the lack of end-user loyalty to communities in this study can be explained by several factors that go beyond the social, the social motivational factor may also be regarded as the most important in our results. Furthermore, data show that aspects related to "ease of use" community design, in terms of features, content variation and usability, are important. The second most important factor was low content issues, and the third most important reason to stop using communities is due to usability issues.

Harassment and bullying are also reported as a critical factor for a lower level of community loyalty. Thus, factors such as trust, harassment and moderation could also be regarded as social factors, or the sociability of the communities.

\subsection{Discussing the factors}

\subsubsection{Lack of interesting people/friends}

Firstly, the most frequently reported reason was that people inside the community were too dissimilar to each other or that users lacked friends in the community. It is well-known that people want to be part of a group of peers whom they respect and like and whose values they share. Previous research does suggest that empathy is strongest between similar people and people who share similar experiences $[1,4,5,14,9]$. In fact, the more similar people are, the easier it is for them to understand each other [1]. It is therefore important to create social spaces that facilitate interaction with other users to share opinions, concerns, and passions.

Designing for small communities, or small groups inside the community, with the focus of a common interest or purpose, may be a solution to avoid the lack of interesting people. Another solution is to make it easy to invite friends to the community people are attending. Facebook is an example of how important this is, and may be part of the explanation of the popularity of Facebook. You can invite people by looking for them or discovering them. You can search for people by name or discover them in a network, group, or a friend's profile. Second, you can add the email addresses of people you want to invite. Third, you can invite people through your email address book. This is made possible by allowing Facebook to access your email addresses on popular email programs like MSN Hotmail, Gmail, AOL, and Yahoo!. Facebook will check to see if your friends are already on Facebook or not, and invite them accordingly.

\subsubsection{Low quality content}

This study revealed that the second most frequent reason to stop using or use a community to a lesser extent is too much boring content and repetition, too few updates, and too few features giving the users opportunities to create their own content. Another reason was that the content did not fit the user's needs, users did not find it useful or it was not relevant to the community.
The usual method for increasing loyalty on the Web is to have fresh content that changes on a regular basis. Several participants communicated that they easily got bored. This may due to some of the same reasons for member complaints regarding the types of people present in the community. If people dissimilar to you are attending, you may dislike their preferences for content or have different interests or purposes for joining the community. The reason people have to come back is that they find it interesting.

People require content that is interesting and varied, as well as targeted towards the user group in the community. Preece [17] therefore demonstrates that changing content, e.g., through news broadcasts and discussions, is critical for the community. Another way of dealing with this is to encourage provocateurs and others to stimulate social interaction. Enabling tools for "easy to publish" user generated content will also be a key for Community 2.0 environments.

\subsubsection{Low usability}

That low usability should be such an important issue for community-loyalty may be surprising for some, since online community usage is an entertaining and engaging activity that most people pursue in their leisure time. In addition, it is also mainly young people that so far use these kinds of activities online. Young people are often seen as technologically savvy people that can cope well with a messy and complex user interface.

Thus, a reason for the importance of usability might be that most users of online communities are not ready to use all the applications and the multi-media opportunities that are available to them. As suggested in the introduction: online communities or Community 2.0 of today are often complex systems. This may indicate a gap concerning the transition from text to a multimedia environment. As a matter of fact, today most users cannot create, manage and share multimedia digital content as easily as they can manipulate text, for example in chat rooms, email and word processing programs. A new study has suggested that for most community-members, submitting video or audio are rather rare activities [2].

The second gap concerns the transition from online communities controlled mainly by professional users to online communities that are also controlled by non-professional users. The fact that several different types of non-professional users attend such communities makes it important for designers to place a priority on infrastructures designed to support the formation of workable communities that are "easy to use" by a wide audience. It will be important to help individuals engage within communities in a way that is likely to prompt beneficial responses and build commitment [1].

\subsubsection{Harassment/bullying}

The findings related to harassment and bullying in this study are in line with other research. In general, hostile, aggressive communication has been identified as a significant negative aspect of text-based mediated communication. There is more or less a consensus that hostile or aggressive communication occurs in mediated environments [13].The level of hostility experienced in the community environment might, however, decrease if 
developers try to make communities where the norm is to identify users with real names, such as with Facebook.

The participants in our study that suffered from such hostility were mainly reporting communities where users choose nicknames. Anonymity using communication technologies is often regarded as a facilitator of a more negative outcome in terms of aggression and hostility or "flaming" [13, 17], and should therefore be avoided in community settings online.

Finally, several of the communities users that experienced harassment discussed have quite a bad reputation because they are sex related. Harassment may, therefore, not follow the person, but rather the community.

\subsubsection{Time-consuming/isolating}

That people feel they do not have time or that they waste time by attending online communities may be hard to do anything about. If people do not have time, mobile solutions for the community may be an idea. However, time is also about motivation. If the community is good enough, people will, of course, have time for it.

One factor that may explain this lack of motivation is that at this point several of the communities are quite immature. They do not provide enough good reasons to stay in the community. A community user should not just feel entertained, but also productive. Therefore, wiki solutions, which help people to share and create content, must be easier to use. There should also be more applications and functions inside communities that might support work-related and information-related services.

A final factor related to this category was that some users thought online communication was not a proper substitute for face-to-face communication. Therefore, they argued that community membership online could result in social isolation. The development of future online communities should thus take into account the possible social impact they may have on people's everyday life

\subsubsection{Low trust}

As in the section about harassment and bullying, the aspect of anonymity versus real identities is also an issue related to trust. A low level of trust was the fifth most important reason for low community commitment. Participants reported fake identities as a large threat and regarded this as a non-serious use of the community.

According to Fukuyama, trust can be defined as: "the expectation that arises within a community of regular, honest and cooperative behavior, based on commonly shared norms, on the part of the members of the community" [17]. Methods of supporting and managing trust in online communities are also recognized to be central $[11,17]$. Communities should therefore support long-term relationships and interactions among peers or like-minded people. Secondly, communities should support non-anonymity. Thirdly, they should make features available that support privacy among users.

\subsubsection{Over-commercialized}

The study found some resistance to community commercialism among members (6\%). Most people may view the Internet as a free world where they can entertain and interact with other people at no cost. Some people or community members also "work" for free inside the community by adding user generated content. Community designers or owners should therefore strive for low commercialized communities, with discreet commercials. This issue lacks research, and a viable business model for online communities still seems quite vague.

\subsubsection{Dissatisfaction with moderators}

The moderator is a key person in many communities. This was the lowest frequent reason (1\%) reported for being disloyal to a community. However, it should still be mentioned as an important issue. Moderating a community is very hard and requires a lot of effort, but pays off in terms of establishing the community. At a later stage, some volunteer members of the community can themselves become moderators, creating a kind of ownership. Community owners should listen to their community and make tools available for feedback and suggestions among members, as well as asking them what they require.

\subsection{Future work}

This paper is an initial step to investigate end-users' lack of loyalty to their online community or communities. If a good online community is built, users will come; however, if they only visit once, the community will fail. This is one of the reasons why raw "hit rates" are discredited as a measure of site success. Asking users or measuring user activity over time is a more appropriate approach. The results in this paper have shown that there are several factors that must be investigated and taken into account.

The social factor, the content-factor, the usability-factor and the harassment/bullying factor seems to be the most important. Future work should therefore look more closely at these themes, and in a more quantitative way. Qualitative or interpretive studies are prominent in the research on communities. An approach combining different types of methods, both quantitative and qualitative, should therefore be applied in the future. This could also give more insight into the importance of background variables such as gender and age related to user loyalty.

\subsection{Limitations}

This study looked at end-user loyalty and self-reported causes for its lack, by using one open question in an online survey. With 5723 respondents, we needed to reduce this comprehensive content to a controllable set of user statements. 200 user statements from the responses containing the highest number of words were chosen. This, of course, limits the data available. On one hand, we only obtained statements from people that wrote extensively, but on the other hand we avoided sifting through user statements that lacked meaning or had a low information value.

Finally, we had no control mechanism to determine whether the participants actually wrote truthfully, or if they were just making things up. These statements should therefore have been followed up by real-life interviews. However, the online material and the users' responses seem to be written in a truthful manner. 


\section{CONCLUSION}

This study researched end-user loyalty to online communities. By using qualitative data from an extensive online survey of online community users and a representative sample of Internet users, 200 community-users and their responses to an open question regarding community-loyalty were analyzed.

Keeping current users as loyal members is the single most important factor for a successful online community. Thus, an important fact is that online communities are often a tool to build loyalty to a website or a company or brand, which makes it even more important to ensure loyalty for the community. The study found that users lose loyalty to online communities because of the following reasons:

1. Few interesting people/friends attending

2. Low quality content

3. Low usability

4. Harassment/bullying

5. Time-consuming/isolating

6. Low trust

7. Over-commercialized

8. Dissatisfaction with community-moderators

9. Unspecified boring

Lack of interesting people or friends is the most frequent reason for leaving or using an online community less. This has been regarded as the important "social factor" for communities. Thus, the other reasons identified, such as low trust, harassment and dissatisfaction with moderators must also be regarded as social factors, or the sociability of the community. Sociability focuses on the social interaction.

However, to fully understand community-loyalty, it is essential to also include an "ease of use" or usability factor into the community design. One important reason to take usability seriously is that online communities often include a wide range of services and applications that make the service more complex for the users. Finally, it is necessary to include varied, good and original content in the community by supporting tools for user generated content production.

\section{ACKNOWLEDGMENTS}

We would like to thanks the IST and the CITIZEN MEDIA Project supported by the European Commission, and the RECORD Project supported by the Norwegian Research Council. I would also thank the communities and users who participated in the study as well as Asbjørn Følstad at SINTEF ICT.

\section{REFERENCES}

[1] Arguello, J., Buttler, B., Joyce, E., Kraut, R., Ling, K., Wang, X. and Rose, C., Talk to Me: Foundations for Successful Individual-Group Interactions in Online Communities in SIGCHI Conference on Human Factors in Computing Systems, CHI'06, (Montréal, Québec, Canada,, 2006), ACM Press, New York, 959 - 968.
[2] Brandtzaeg, P.B. and Heim, J. Participation in Online Communities Brandtzaeg, P.B. ed. Initial context, user and social requirements for the CITIZEN MEDIA applications, EU Commision, Brussel, 2007.

[3] Brandtzæg, P.B., The Innovators in the New Media landscape: User trends and challenges in the broadband society. in Cost 298 Conference - The Good, the Bad and the Unexpected. Participation in the broadband society: Users as innovators, (Moscow, Russia, 2007).

[4] Brandtzæg, P.B., Følstad, A. and Heim, J. Enjoyment. Lessons from Karasek. in Blythe, M.A., Overbeeke, K., Monk, A.F. and Wright, P.C. eds. Funology: from usability to enjoyment, Kluwer, Dordrecht, the Netherlands, 2003, 55-65.

[5] Butler, B.S. Membership Size, Communication Activity, and Sustainability: A Resource-Based Model of Online Social Structures Information Systems Research,, 12 (4). 346-362.

[6] Diker, V. A Dynamic Feedback Framework for Studying Growth Policies in Open Online Collaboration Communities 10th Americas Conference on Information Systems, New York, 2004.

[7] Geerts, D., Obrist, M., Brandtzæg, P.B. and Tscheligi, M. Supporting non-professional users in the new media landscape SIGCHI Conference on Human Factors in Computing Systems, CHI'07., ACM Press, New York, San Jose, California, USA, 2007.

[8] Hackos, J. and Redish, J. User and Task Analysis for Interface Design. Wiley, New York, 1998.

[9] Heim, J., Brandtzaeg, P.B., Kaare, B.H., Endestad, T. and Torgersen, L. Children's usage of media technologies and psychosocial factors New Media Society, 9 (3). 425-454.

[10] Holstie, O.R. Content Analysis for the Social Sciences and Humanities. Addison Wesley (Current Publisher: Perseus Publishing), Reading, MA 1969.

[11] Kim, A.J. Community Building on the Web: Secret Strategies for Successful Online Communities. Peachpit Press, Berkely, 2000.

[12] Kollock, P. Design Principles for Online Communities PC Update, 1998, 58-60.

[13] Kaare, B.H., Brandtzæg, P.B., Heim, J. and Endestad, T. In the Borderland Between Family orientation and Peerculture: The Use of Communication Technologies among Norwegian Tweens. New Media \& Society, 9 (4). 603-624

[14] Levine, J.M. and Moreland, R.L. Group socialization. in Hewstone, W.S.M. ed. Theory and research in European review of social psychology, John Wiley \& Sons, New York, 1994.

[15] OFCOM. The Communications Market 2006 report, OFCOM, London, UK., 2006.

[16] Peck, R.S., Zhou, L.Y., Anthony, V.B. and Madhukar, K. What Should Yahoo Do Regarding Social Networks?, Bear Stearns New York, 2007. 
[17] Preece, J. Online Communities: Designing Usability, Supporting Sociability. John Wiley \& Sons, Chichester, UK, 2000.

[18] Rheingold, H. The Virtual Community: Homesteading on the Electronic Frontier. MIT Press, New York 2000.

[19] Sassenberg, K. Distributive Justice in Common-Bond and Common-Identity Groups Group Processes \& Intergroup Relations, 5 (2). 151-162.

[20] Stutzman, F. An Evaluation of Identity-Sharing Behavior in Social Network Communities. International Digital and Media Arts Journal, 3 (1 ).
[21] Waterson, P. Motivation in Online Communities. in Dasgupta ed. Encyclopedia of Virtual Communties 2006.

[22] Wikipedia. Virtual Community Wikimedia Foundation, Inc. USA, 2007.

[23] Wunsch-Vincent, S. and Vickery, G. Participative web: user-created content. Organization for Economic Cooperation and Development, OECD,, Brussels, 2006. 